\title{
"Abscopal" Effect of Radiation Therapy Combined with Immune-Therapy Using IFN- $\gamma$ Gene Transfected Syngeneic Tumor Cells, in Rats with Bilateral Implanted N29 Tumors
}

\author{
Bertil R. R. Persson, ${ }^{1,2}$ Catrin Bauréus Koch, ${ }^{1,2}$ Gustav Grafström, ${ }^{1,2}$ Crister Ceberg, ${ }^{1,2}$ \\ Per Munck af Rosenschöld, ${ }^{1}$ Henrietta Nittby, ${ }^{2,3}$ Bengt Widegren, ${ }^{2,4}$ and Leif G. Salford ${ }^{2,3}$ \\ ${ }^{1}$ Department of Medical Radiation Physics, Lund University, 22185 Lund, Sweden \\ ${ }^{2}$ Rausing Laboratory, Biomedical Centre, Lund University, 22185 Lund, Sweden \\ ${ }^{3}$ Department of Neurosurgery, Lund University, 22185 Lund, Sweden \\ ${ }^{4}$ Department of Tumor Immunology, Lund University, 22185 Lund, Sweden
}

Correspondence should be addressed to Bertil R. R. Persson, bertil_r.persson@med.lu.se

Received 22 June 2011; Accepted 7 August 2011

Academic Editors: A. Clayton, S.-I. Fujii, F. Granucci, and A. Porgador

Copyright ( 2011 Bertil R. R. Persson et al. This is an open access article distributed under the Creative Commons Attribution License, which permits unrestricted use, distribution, and reproduction in any medium, provided the original work is properly cited.

The tumor growth rate response was studied on N29 rat glioma tumor cells subcutaneously implanted on both hind legs of Fischer344 rats. At around 30 days after inoculation, RT was given with ${ }^{60} \mathrm{Co}$ gamma radiation with 4 daily fractions of 5 Gy only to the right-lateral tumors. At days 26, 42, and 54 after inoculation, immunization was performed with irradiated syngeneic IFN $\gamma$-gene transfected cells. Tumor growth rate (TGR \% per day) of the right-lateral irradiated tumor was significantly decreased $(P<0.01)$ after RT alone and with the combination of RT and immunization. But immunization alone gave no significant decrease of the TGR but significantly increased time of survival. The TGR of the unirradiated left-lateral tumors was significantly decreased $(P<0.02)$ only in the group of rats treated with RT alone. It is apparent that tumor cells killed by the radiation mediate suppression of tumor cells outside the target area. This effect is called the abscopal effect.

\section{Introduction}

Radiation therapy (RT) is usually focused on delivering the highest possible absorbed dose to the clinical target volume to destroy the tumor cells without exceeding the tolerance of surrounding normal tissue [1-3]. Effects on tumor cells outside the treated target area are mostly not considered in conventional radiation therapy regimes. In recent years, however, it has become increasingly apparent that radiation therapy can have an effect in tissues outside the immediate location of the radiation beam [4-7].

Nagasawa and Little (1992) observed that cells hit by $\alpha$ particles, and neighboring cells without any hit, both exhibit the same type of damage. The phenomenon was called "bystander effect" borrowed from the field of gene therapy $[8,9]$. Since then several reports and reviews have appeared dealing with this kind of nontarget effect also in vivo [10-19].
The bystander effect is, however, not often observed clinically $[1,16,20]$.

Effects of radiation therapy on tumors outside of the radiation field have, however, been reported in many malignancies [1, 2, 21-30]. This phenomenon was originally described as abscopal effect by Mole in 1953 [31]. The definition of abscopal effect comes from the Latin ab (position away from) and scopus (mark or target).

The abscopal mechanism of action is still not fully explained, although it has been hypothesized that a variety of underlying biological events might contribute to the effect, including immune reactions and inflammatory response [32-34]. Immune-mediated abscopal effect has been observed in mice with 67NR tumor after RT with 2 or 6 Gy [5] and by studying the number of available dendritic cells (DCs), using the growth factor Flt3-Ligand(Flt3-L) [35]. Radiation therapy seems to augment the ability of 
DCs to capture tumor antigens, for further homing to the draining lymph node, thereby mediating an effective antigen presentation that might play a vital role on the abscopal effect [36].

We have recently shown a strong enhancement of the therapeutic effect in intracranial N29 tumors by combining a single fraction of radiation therapy ( 5 as well as $15 \mathrm{~Gy}$ ) and immunization with interferon-gamma (IFN $\gamma$ ) transfected immunogenic tumor cells [37, 38]. Previously we also presented a study demonstrating the abscopal effect of radiation therapy in a model of collaterally implanted N29 tumors in rats [6]. In the present study, we have used the same model of collaterally implanted tumors on both hind legs $[6,39]$, to investigate the non-target effect of radiation therapy combined with immunetherapy using IFN $\gamma$-gene transfected syngeneic tumor cells.

\section{Materials and Methods}

2.1. Animals. We used inbred female and male Fischer344 rats weighing around $190 \mathrm{~g}$ and $370 \mathrm{~g}$, respectively. The strain was maintained by continuous, single-line brother to sister mating in our laboratory. During the experiment, the rats were housed in a climate controlled cabinet. In the mean time, they were kept in Macralon cages provided with food pellets and water ad libitum. All experimental animal procedures were approved by the Animal Ethical Committee in Malmö/Lund (Lunds tingsrätt, Box 75, 22100 Lund Sweden).

The animals were observed daily for symptoms of the growing tumors, such as losing weight, unwillingness to move, shaggy fur, and reddening of the eyes and nose. When an animal developed such symptoms or the largest tumor exceeded $9 \mathrm{~cm}^{3}$, it was euthanized.

The experiments A, B, C, and D were performed at different occasions over about one year. At the first experiment, A only 8 control rats ( 4 male and 4 female) were studied. The most extensive experiment was $\mathrm{B}$, with 8 rats $(5$ male and 3 female) in each treatment group RT, IMU-IFN $\gamma$, and the combination IMU-IFN $\gamma+$ RT. This experiment had two groups of controls with 8 rats in each: Gr 11 (5 male and 3 female) (see Figure 2(a)) and Gr 12 (4 male and 4 female). The 3rd experiment involved 8 control rats, and 9 rats were immunized. In the 4th experiment D, 7 rats ( 4 male 3 female) were used as controls, 7 ( 4 male and 3 female) rats were irradiated, and 2 rats were immunized. We aimed to have 8 rats ( 4 male and 4 female) in each group, but, due to the circumstances in breeding and competition with other experiments, the number and female/male ratio of rats in each group could vary. The number of controls and animals treated with radiotherapy (RT), immunization $($ IMU-IFN $\gamma$ ) or a combination (RT + IMU-IFN $\gamma$ ) of the two is summarized in the following Table 2 . In total, 81 rats were involved in the entire study Table 1.

2.2. Cell Lines. The rat glioma $\mathrm{N} 29$ cell line was induced by administration of ethyl-N-nitro urea to 17-18-days pregnant Fischer rats. At 205 days, after administration, $80-90 \%$ of the
TABLE 1: Number of rats entered into each experimental series and groups of treatment.

\begin{tabular}{lccccc}
\hline Exp. series & Controls & RT & IMU-IFN $\gamma$ & IMU-IFN $\gamma+$ RT & All \\
\hline A & 8 & & & & 8 \\
B & 16 & 8 & 8 & 8 & 40 \\
C & 8 & & 9 & & 17 \\
D & 7 & 7 & 2 & & 16 \\
\hline All & 39 & 15 & 19 & 8 & 81 \\
\hline
\end{tabular}

TABle 2: Time of immunization after inoculation (days) in the different groups of animals in series-B, -C, and -D.

\begin{tabular}{lcccc}
\hline $\begin{array}{l}\text { Injection } \\
\text { No. }\end{array}$ & Series B & $\begin{array}{c}\text { IMU-IFN } \gamma \\
\text { Series C }\end{array}$ & Series D & $\begin{array}{c}\text { IMU-IFN } \gamma+\text { RT } \\
\text { Series B }\end{array}$ \\
\hline 1st & 23 & 22 & 27 & 31 \\
2nd & 37 & 36 & 41 & 44,51 \\
3rd & 51 & 50 & 55 & 61 \\
\hline
\end{tabular}

offspring developed tumors in the central or peripheral nervous system. The cell line has been successfully propagated both in vitro and in vivo.

All cells were cultured in antibiotic-free RPMI-1640 medium supplemented with $5-10 \%$ fetal calf serum, $2 \mathrm{mM}$ L-glutamine, $10 \mathrm{mM}$ HEPES, $0.5 \mathrm{mM}$ pyruvate, and $0.096 \%$ $\mathrm{NaHCO}_{3}$. Cell cultures were regularly checked for contaminating microbes by staining with the fluorescent dye Hoechst 32 258, examined with fluorescent microscopy. Cultures with suspected Mycoplasma infection were eliminated or treated with Mycoplasma Removal Agent (Hoechst, Germany) twice with 7 days interval and repeatedly confirmed free of infection. The cell cultures were maintained in culture flasks (Nunc, Denmark) and harvested by treatment with trypsin/EDTA.

2.3. Transfection of Cells for Immunization. Cells used for immunization were $\mathrm{N} 29$ tumor cells which were IFN $\gamma$ gene transfected to enhance secretion of interferongamma. The IFN $\gamma$ gene (The GenBank accession number for the genes is IFN $\gamma$, no. AF010466) was inserted into the cloning site (either the BamHI or the EcoRI sites) of the retroviral vector pLXSN (GenBank accession no. M28248n). The gene constructs were sequenced, and $5 \mu \mathrm{g}$ of plasmid DNA was subsequently used to transfect the retroviral packaging cell line GP1E86. Transfectam (Promega, Madison, Wis.) was used for transfect ion, according to the protocol of the manufacturer. The cell colonies which produced the highest number of retroviral particles were selected. Supernatants of these cells were used to infect the tumor cells. The infected tumor cells were cultured on selective media (Geneticin), and several single-cell clones were selected by limiting dilutions. The clones were checked for expression by either Northern blot analysis or semiquantitative polymerase chain reaction, and verified by studying the expression of the protein. After cell cloning, IFN $\gamma$ production was evaluated by ELISA in supernatants that were harvested from tumor cells plated in 48 -well plates, incubated for 48 hours at $37^{\circ} \mathrm{C}$, and confirmed as $70 \mathrm{ng} / 10^{6}$ cells. For immunizations, cells were 
cultured for 1 week, washed twice, and suspended in medium [40].

2.4. Inoculation and Treatment of Subcutaneous Tumors. The rat glioma N29 was induced in our laboratory by subcutaneous administration in the hind legs. Two hundred thousand $(200000)$ cells were inoculated into the right leg whilst 50000 cells were inoculated into the left leg in order to simulate a secondary smaller tumor. The tumor volume was estimated as an ellipsoid by length, width, and thickness measured with a caliper. When a tumor reached a volume of about $9 \mathrm{~cm}^{3}$, was euthanized for ethical reasons. Tumors were treated about 4 weeks after inoculation when a solid tumor had developed with a diameter of $1-1.5 \mathrm{~cm}$. Before treatment of the tumors, animals were anesthetized with 5\% chloral hydrate given intraperitoneally (i.p.).

\subsection{Immunization with IFNy Gene Modified N29 Tumor Cells.} The adenovirus transfected cells were transferred from the culture flasks with a cell density of $2 \times 10^{4}$ cells $/ \mathrm{mL}$ in serumfree medium (IMDM-0) to $15 \mathrm{~mL}$ centrifuge test tubes (Nanclon) and stored in a melting ice bath before irradiation. The cells were radiation sterilized with an absorbed dose of $70 \mathrm{~Gy}$ in a Gammacell 2000 (Mølsgaard Medical, Risø, Denmark) at a dose rate of $4.0 \mathrm{~Gy} / \mathrm{min}$. During the irradiation, the cells were kept at room temperature. Directly after the irradiation they were placed in a melting ice bath. The sterilized cells are not proliferating but are secreting IFN $\gamma$ for some time after administration to the rat.

The first immunization with sterilized cells was given five days before the radiation treatment and then two more times with 14-day intervals see Table 2. Immunization was performed with $3 \cdot 10^{6} \mathrm{IFN}_{\gamma}$ gene modified N29 tumor cells injected intraperitoneally.

2.6. Radiation Treatments. Radiation treatments were performed at around 30 days after inoculation. Before radiation therapy, the animals were anesthetized with $5 \%$ chloral hydrate given intraperitoneally (i.p.) or Ketalar/Rompun, 0.55 $\mathrm{mL} / 100 \mathrm{~g}$.

Animals were given fractionated radiation treatment using a ${ }^{60} \mathrm{Co}$ radiotherapy unit (Siemens Gammatron S) with a source-skin distance (SSD) of $50 \mathrm{~cm}$ and the maximum absorbed dose rate $0.65-0.70 \mathrm{~Gy} / \mathrm{min}$. A $0.5 \mathrm{~cm}$ thick, tissue-equivalent bolus (Super Flab, Mike Radio-nuclear instruments inc. NY, USA) was placed over the tumor to achieve full-dose buildup and a more homogeneous dose distribution in the tumor. The radiation field size was collimated to cover the tumor area with a margin of at least $1 \mathrm{~cm}$ (Figure 1).

The absorbed dose to the exposed right-lateral tumor was $5 \mathrm{~Gy} /$ day delivered at 4 consecutive days, that is, in total $20 \mathrm{~Gy}$. The absorbed dose to the left-lateral tumor was less than $0.1 \mathrm{~Gy}$. In previous experiments $20 \mathrm{~Gy}$ was shown to be suboptimal and noncurative dose suitable for studies of nontarget effects [41]. The absorbed dose at various locations was measured both with an ionization chamber and TLD chip placed under the bolus.

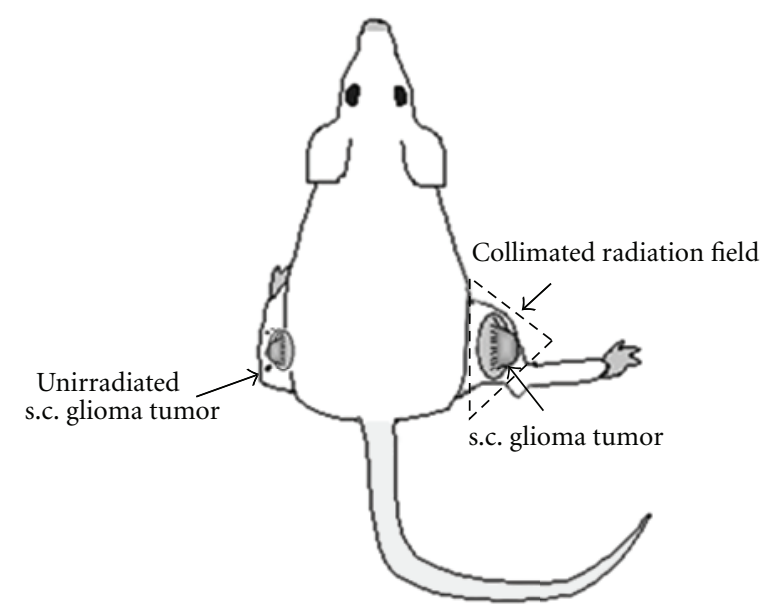

Figure 1: Experimental setup for radiation treatment.

\subsection{Model for Tumor Growth Analysis and Synergistic Enhancement}

2.7.1. Tumor Growth Rate (TGR). The tumor volume of each tumor was measured five days a week and fitted to a model of exponential growth. The tumor volume growth rate (TGR) of each individual tumor was estimated according to the following equations:

$$
\begin{gathered}
\frac{\partial \mathrm{TV}}{d t}=\mathrm{TGR} \cdot \mathrm{TV}, \quad \mathrm{TV}=\mathrm{TV}_{0} \cdot e^{\mathrm{TGR} \cdot\left(t-t_{0}\right)}, \\
\ln [\mathrm{TV}]=\ln \left[\mathrm{TV}_{0}\right]+\mathrm{TGR} \cdot\left(t-t_{0}\right),
\end{gathered}
$$

where TV is tumor volume at time $t$ after inoculation, TGR is tumor growth rate constant day-1, TV0 is tumor volume at the time of radiation treatment $t=t_{0}$.

The TGR value was evaluated for each individual rat by a linear fit of $\ln (\mathrm{TV})$ at $t>t_{0}$.

2.7.2. Specific Therapeutic Effect (STE). The ratio of the tumor volume of the exposed tumor and corresponding control is a measure of the apparent surviving fraction, SF, of the cells in the treated tumor

$$
\mathrm{SF}=\frac{\mathrm{TV}_{\text {Exposed }}}{\mathrm{TV}_{\text {Control }}} .
$$

The therapeutic effect, TE, is a measure of the number of lethal events that has occurred in the cells of the treated tumor volume and thus defined as

$$
\mathrm{TE}=-\ln (\mathrm{SF})=\left[\mathrm{TGR}_{\text {Control }}-\mathrm{TGR}_{\text {Exposed }}\right] \cdot t .
$$

In order to get a therapeutic effect measure independent of time, a quantity named "specific therapeutic effect" STE is defined. That is the tumor growth rate difference between the control and exposed tumor divided by tumor growth rate of the controls

$$
\mathrm{STE}_{i}=\frac{\overline{\mathrm{TGR}}^{c}-\mathrm{TGR}_{i}^{E}}{\overline{\mathrm{TGR}}^{c}},
$$


where $\mathrm{TGR}_{i}^{E}$ is the individual tumor growth rate constant $\left(\mathrm{day}^{-1}\right)$ of exposed rats. $\overline{\mathrm{TGR}}^{c}$ is the average of the individual tumor growth rate constant $\left(\mathrm{day}^{-1}\right)$ in the group of unexposed control rats.

The STE is equal to 0: when the average of tumor growth rate constant of the exposed group is equal to the average of the tumor growth rate constant of the control.

The STE is equal to 1: when the average tumor growth rate constant of the exposed group is equal to 0 , which means arrested tumor growth.

The STE is larger than 1: when the average tumor growth rate constant of the exposed group is negative $(<0)$, which means a declining tumor volume.

2.7.3. Specific Abscopal Effect (SAE). The "specific abscopal effect" SAE is defined as the tumor growth rate difference between the left-lateral unexposed tumor and corresponding control average divided by tumor growth rate of the average of left-lateral controls

$$
\mathrm{SAE}_{i}=\frac{\overline{\mathrm{TGR}}^{\mathrm{UC}}-\mathrm{TGR}_{i}^{\mathrm{UE}}}{\overline{\mathrm{TGR}}^{\mathrm{UC}}},
$$

where $\mathrm{TGR}_{i}^{\mathrm{UE}}$ is the individual tumor growth rate constant of the unexposed (UE) left-lateral tumors in the group of $\mathrm{N}$ exposed rats. $\overline{\mathrm{TGR}}^{\mathrm{UC}}$ is the average of the individual tumor growth rate constant in the left-lateral tumors in the group of unexposed controls (UCs).

2.7.4. Therapeutic Effect Enhancement Ratio (TER). The enhancement effect the combined treatments is the ratio of the effect of the experimental combination $\left(\mathrm{STE}_{\mathrm{comb}}\right)$ of the various treatment modalities and the therapeutic effect the hypothetically independent and additive combination of single treatment modality ( $\left.\mathrm{STE}_{\text {ind }}\right)$.

The therapeutic effect enhancement ratio of the exposed tumors is thus defined as:

$$
\mathrm{TER}=\frac{\mathrm{STE}_{\mathrm{comb}}}{\sum_{i} \mathrm{STE}_{\mathrm{ind}, i}} .
$$

2.7.5. Abscopal Effect Enhancement Ratio (AER). The abscopal enhancement ratio of the left-lateral unexposed tumor is defined as

$$
\mathrm{AER}=\frac{\mathrm{SAE}_{\mathrm{comb}}}{\sum_{i} \mathrm{SAE}_{\mathrm{ind}, i}} .
$$

The enhancement ratios TER and AER are measures of any synergistic or diminishing effect obtained in the combination of the various treatment modalities. It may be due to interaction of sublethal lesions induced by both treatment modalities to produce lethal events that cause the enhancement ratio $>1$. If the individual treatment modality is highly aggressive by itself, there might, however, also be an "over killing" effect that reduces the effect compared to the additive action, so that enhancement ratios $<1$. It is thus important to investigate the effect of combined treatments at various dose levels to find the maximum value of enhancement ratios.

2.8. Proliferation Assay. Nonadherent spleen cells (300 000/ well) were plated onto 96-well flat-bottom plates and cultured with N29 glioma cells (15000/well) for 5 days. Coculture of nonadherent spleen cells with adherent spleen cells of rats from the various groups was performed by allowing 200000 spleen cells (not previously subjected to plastic adherence) to adhere for $120 \mathrm{~min}$ in 96-well plates after which the non-adherent cells were removed.

Various numbers $(50000,150000$, or 450000$)$ of nonadherent spleen cells were added to these plates. The cells were cultured with Staphylococcal Enterotoxin A (SEA, $1 \mathrm{ng} / \mathrm{mL}$ ) in the presence of N-nitro-L-arginine methyl ester (L-NAME, Sigma Chemical Co St Louis, Mo, USA).

Tritium-labeled thymidine $\left({ }^{3} \mathrm{H}\right.$-Thymidine) was added and kept during the final $6 \mathrm{~h}$ of culture. The cells were harvested on filter papers, scintillation fluid was added, and the radioactivity of the cells collected on the filter papers was measured in a beta counter (Wallac Microbeta, Turku, Finland). The recorded count rate in the tritium channel in counts per minute (cpm) was used as a measure of proliferation.

\section{Results}

3.1. Tumor Growth Rate TGR. The volume of each individual tumor was measured during the entire lifetime of all animals in each of the experimental groups. The Fischer-344 rats had N29 glioma tumors implanted on both thighs. But only the tumors on the right lateral side were irradiated.

The tumors are treated with radiation therapy (RT), immunization (IMU-IFN $\gamma$ ), and their combination (RT + IMU-IFN $\gamma$ ). The tumor volume was estimated by daily measurements five days a week. At those occasions the rats were also observed for symptoms from the tumor growth. In Figure 2, the tumor volume is displayed at each time of measurement of the animals of the series-B only. The tumor volume data fit well to an exponential growth model, and the fitted curve for all tumors in each group is displayed as a solid line in each diagram.

Tumor growth rate is estimated from the tumor volume measurements of each tumor fitted to a model of exponential growth,

$$
\mathrm{TV}=\mathrm{TV}_{0} \cdot e^{\mathrm{TGR} \cdot\left(t-t_{0}\right)},
$$

where TV is tumor volume at time $t$ after inoculation, TGR is tumor growth rate constant day ${ }^{-1}, \mathrm{TV}_{0}$ is tumor volume at the time of radiation treatment $t=t_{0}$.

The tumor growth-rate TGR was evaluated for each individual tumor starting at 30 days after inoculation when the radiation therapy took place. In Table 3 are given the averages of the results obtained from the growth rate of both left and right lateral tumors in the various series for controls, 
and those treated with either RT, immunization (IFN $\gamma)$, or their combinations are given.

The average tumor growth rate of the irradiated rightlateral tumor was $4.5 \pm 0.3 \% /$ day which according to $t$ test is significantly decreased $(P<0.001)$ compared to the TGR of the controls $8.4 \pm 0.3 \%$ /day. With immunization alone, however, the TGR $7.6 \pm 0.6 \%$ /day was not significantly decreased compared to the controls. But, in a group given immunotherapy combined with RT, the TGR $5.7 \pm 0.3 \%$ /day was significant decreased $(P<0.001)$ compared to the controls. In the group given RT to the right tumor, the TGR $6.1 \pm 0.4 \% /$ day of the contra lateral unexposed left tumors is significantly $(P<0.001)$ reduced by $33 \%$ compared to the TGR $9.1 \pm 0.3 \% /$ day of their controls. This effect on untreated tumors outside the target of irradiation is called the abscopal effect. In the group given RT to the right tumor combined with immunotherapy, the TGR $7.4 \pm 1.0 \%$ /day of the contra lateral unexposed left tumors is decreased as well, however, not significantly compared to their controls.

Figure 3 displays the averages of the TGR results of all series. The results of the right treated tumors are displayed in blue piles and of the corresponding un-irradiated left-lateral bystander tumors are displayed in red.

3.2. Specific Therapeutic Effect and Specific Abscopal Effect. In order to estimate the therapeutic effect, we used the quantity "specific therapeutic effect" STE. The "specific therapeutic effect" STE is equivalent to the difference in tumor growth rate between the right controls and the right exposed tumors relative to the tumor growth rate of the right controls.

The corresponding quantity "specific abscopal effect" SAE was used for quantifying the abscopal effect. The "specific abscopal effect" SAE is equivalent to the difference in tumor growth rate between the average of the left controls and the left unirradiated tumors of the treated animals relative to the tumor growth rate of the left controls.

The STE and SAE values were calculated for each individual tumor. The values are normalized to the average of the controls of each experimental series and treated as one population. The averages of the results of each individual series are given in Table 4, and the pooled data of series-B, $-\mathrm{C}$, and $-\mathrm{D}$ are displayed in Figure 4.

\subsection{Therapeutic (TER) and Abscopal (AER) Enhancement} Ratios. Therapeutic enhancement ratio (TER) and abscopal enhancement ratio (AER) at combined treatment with RT and IFN $\gamma$ are derived as the ratios of the specific effects of the combined treatments and the sum of single treatments as given in Table 4. The value of the therapeutic enhancement ratio and the abscopal enhancement ratio of the combined treatments are

$$
\frac{0.26}{0.46+0.09}=0.47 \pm 0.07, \quad \frac{0.14}{0.33-0.01}=0.44 \pm 0.12 \text {, }
$$

respectively. Since these values are $<1$, there seems to be no synergistic effects of radiation therapy combined with immune therapy for extracranially implanted N29 glioma tumor.
3.3.1. Result of Proliferation Assay. The proliferation recorded in the spleen cell harvested from the various groups of rat is given in Table 5 as counts per minute recorded by the scintillation counter.

3.4. Result of Time to Sacrifice. When an animal showed symptoms of the growing tumors or the size of the tumor exceeded $9 \mathrm{~cm}^{3}$, it was euthanized of ethical reason. The time of survival in the present study is thus time to sacrifice, which varied within each group and between the groups of various treatments. The result of time to sacrifice for the rats in experiment B where all types of treatments were involved is displayed in Table 6 .

\section{Discussion}

4.1. Tumor Growth Rate (TGR). In the diagrams of Figure 2, it is shown that the tumor volume beyond 20-30 days after inoculation follows an exponential growth model. It is, however, not evident to draw quantitative conclusions out of the average growth curves because of the variation in the time of death between the rats. In order to perform a statistical analysis of the results, the tumor growth rate of each individual tumor is estimated from the daily tumor volume measurements of each tumor at 30 days after inoculation and thereafter. The averages of the results of the tumor growth rate thus obtained are summarized in Table 3, and displayed in Figure 3.

The tumor growth rate of the right-lateral tumor was significantly decreased for treatments with RT $(P<0.0001)$ compared to the controls. With immunization (IFN $\gamma$ ) alone in 19 rats, there was, however, no significant decrease of the TGR of the right lateral tumors compared to the controls. But in a group of 8 rats given the combination of immunization with RT, there was a highly significant decrease of the TGR values $(P<0.001)$ of the right irradiated tumors compared to the controls.

The TGR values are significantly reduced $(P<0.0001)$ on the contralateral unexposed left side in the group of 15 rats treated with RT only on the right tumor. This effect on untreated tumors outside the target of irradiation is called abscopal effect. With immunization (IFN $\gamma$ ) alone in 19 rats and with immunizations in combinations with RT in 8 rats, there were no significant decreases of the TGR in the left lateral tumors compared to the controls. Also the group of 8 rats given the combination of immunization and RT, there was no significant decrease of the TGR values of the left irradiated tumors compared to the controls. This is in agreement with previous findings that cellular immunization gives no antitumor response on tumors that produce immunosuppressive factors [42-44].

According to our previous results on single intracranial N29 tumors, radiation therapy was supposed to decrease the immune suppression by the tumor $[37,38]$. But in the present model with two contralateral tumors the immune suppression by the untreated tumor seems suppress the action of the activated $\mathrm{T}$ cells. 


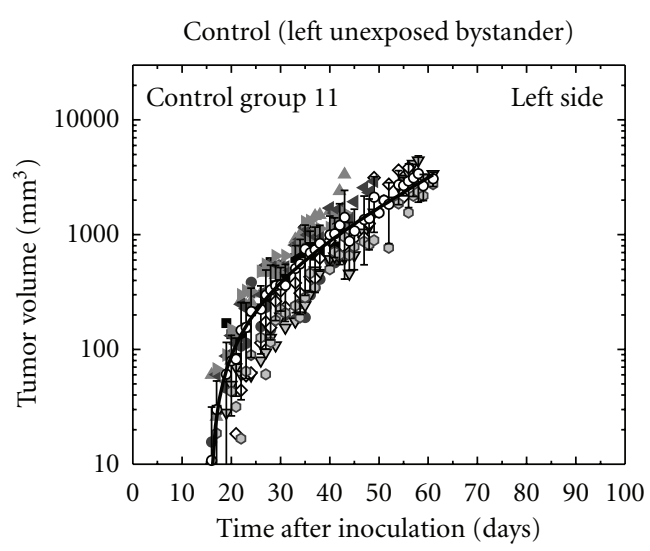

- Rat 5410

- Rat 5411

$\nabla$ Rat 5413

$\diamond$ Rat 5414

4 Rat 5415

> Rat 5416

- Rat 5417

- Rat 5412

al growth fit $r^{2}=0.98$

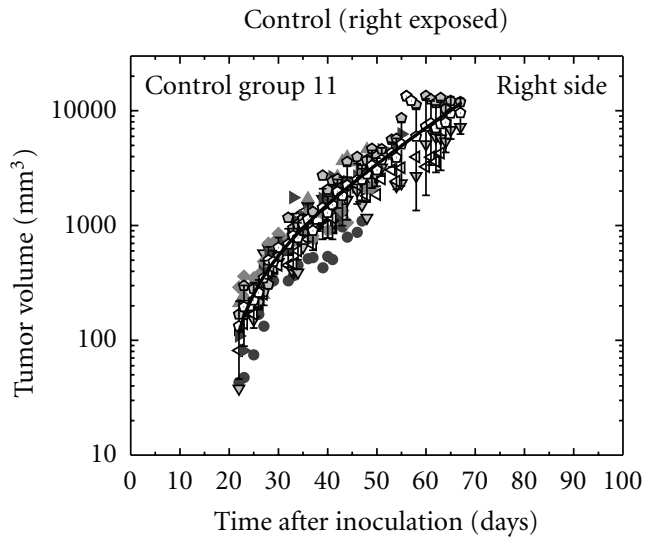

- Rat 5410

- Rat 5411

$\nabla$ Rat 5413

$\triangleleft$ Rat 5414

$\checkmark$ Rat 5417

A Rat 5412

$\rightarrow$ Rat 5415

Rat 5417

$\checkmark$ Average

- Exponential growth fit $r^{2}=0.92$

(a) Tumor volumes at each time of measurement in all tumors of the controls in the series-B

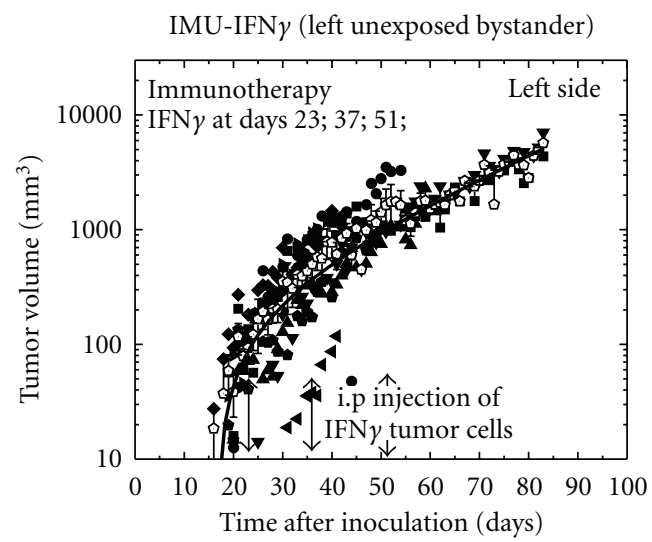

- Rat 5334

- Rat 5341

- Rat 5353

Rat 5356

- Rat 5364

Rat 5369

- Rat 5337

$\checkmark$ Average

Exponential growth fit $r^{2}=0.999$
IMU-IFN $\gamma$ (right exposed)

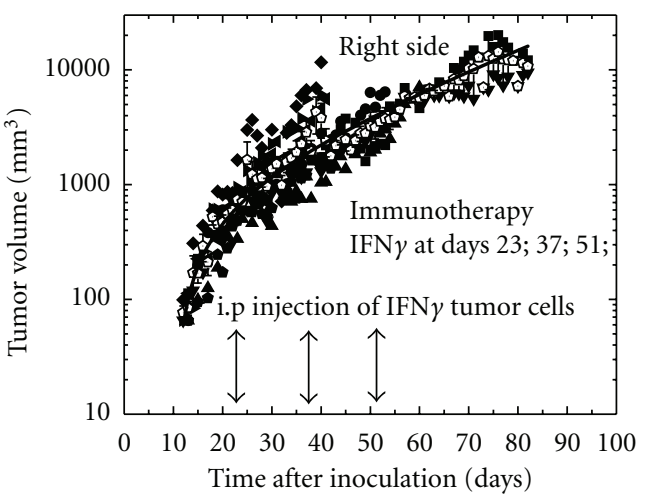

- Rat 5334

- Rat 5341

- Rat 5353

V Rat 5372

$\begin{array}{lll}\text { Rat } 5356 \quad \text { Rat } 533 \\ \text { Rat } 5364 & \text { Average }\end{array}$

— Exponential growth fit $r^{2}=0.997$

(b) Tumor volumes at each time of measurement in all tumors of the IMU-IFN $\gamma$ treated rats in the series-B

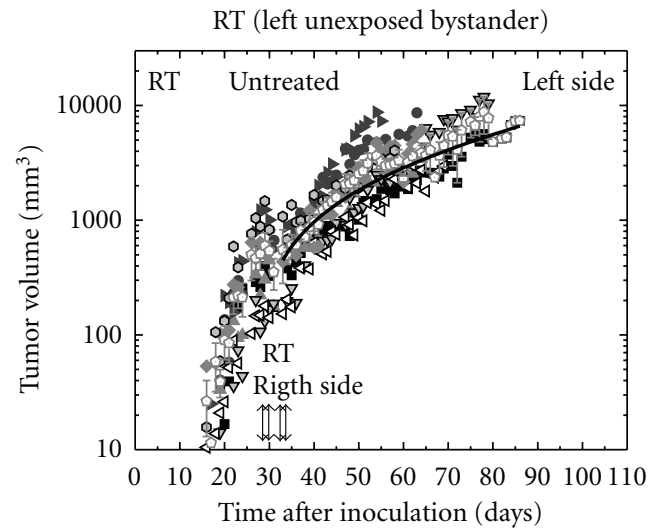

- Rat 5327

- Rat 5336

A Rat 5345

$\nabla$ Rat 5348

$\triangleleft$ Rat 5360

- Rat 5357

Rat 5367

Exponential growth fit $r^{2}$

- Rat 5370

$\checkmark$ Average
RT (exposed)

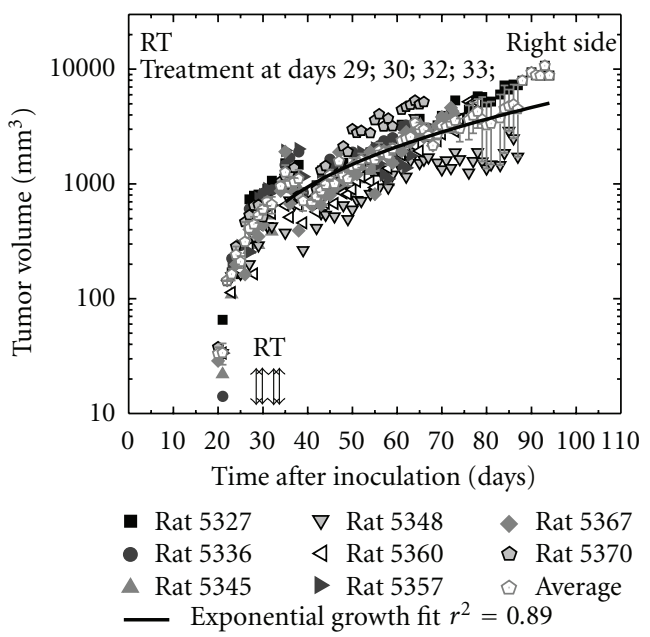

(c) Tumor volumes at each time of measurement in all tumors of the RT group in the series-B

Figure 2: Continued. 

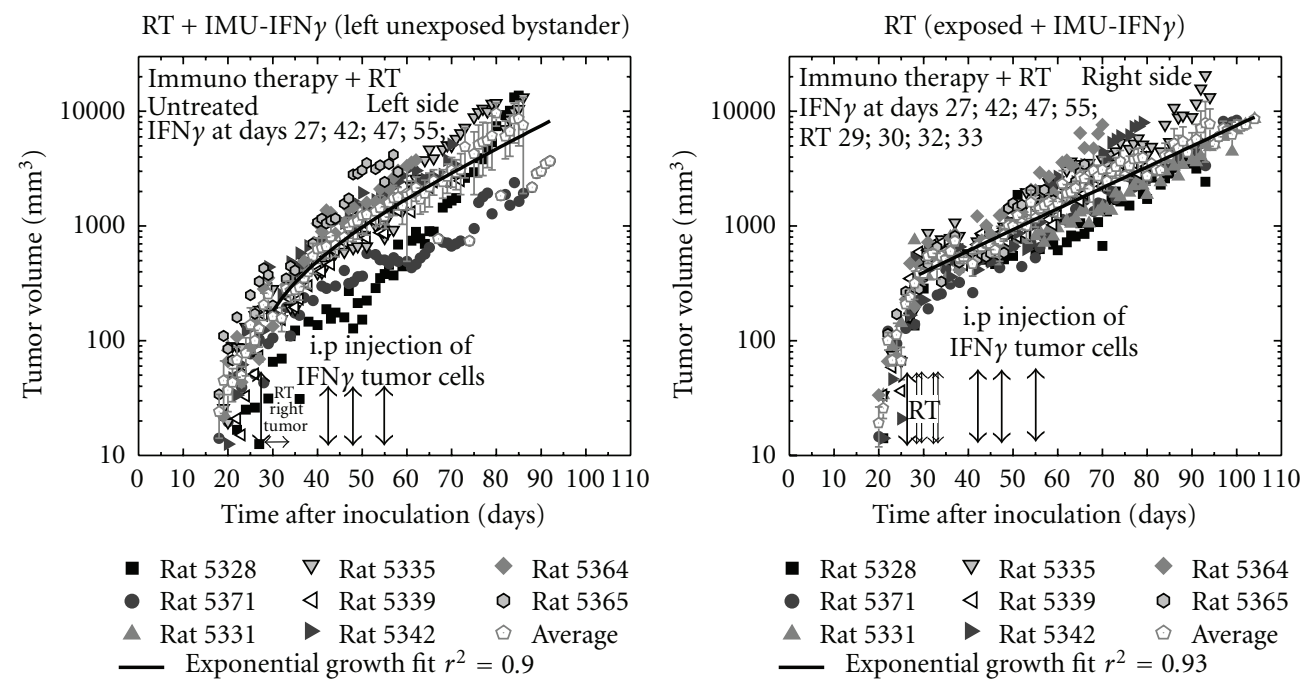

(d) Tumor volumes at each time of measurement in all tumors of the RT+ IMU-IFN $\gamma$ group in the series-B

Figure 2: The left diagrams show the tumor volume of the left-lateral untreated bystander tumors, and the right diagrams show the tumor volume of the right-lateral radiation-treated tumors. The solid lines show the curve fitted by an exponential growth model for $t>t_{0}$, that is, 30 days. In the left diagram of untreated tumors, the asterisk $(*)$ indicates the occasion of radiation treatment of the corresponding right-lateral tumors. In the right diagram for the right lateral treated tumors the thick arrow at "RT exposed" indicates the four radiation treatment fractions. The occasions of immunizations are indicated with double arrows.

TABLE 3: Tumor growth rate (\% per day) of control rats and in rats after immunization with syngeneic IFN $\gamma$ secreting cells (IFN $\gamma$ ). Rightlateral tumors were treated with radiation therapy (RT) while left lateral tumors were not treated. The $P$-values of t-test versus corresponding controls are given in the right columns.

\begin{tabular}{|c|c|c|c|c|c|c|c|}
\hline $\begin{array}{l}\text { Experimental } \\
\text { series }\end{array}$ & Treatment & $\begin{array}{c}\text { TGR left } 50 \mathrm{k} \text { cells } \\
\text { average } \pm \text { SE }\end{array}$ & $N$ & $\begin{array}{c}t \text {-test versus } \\
\text { Ctrl }\end{array}$ & $\begin{array}{c}\text { Irradiated TGR right } \\
200 \mathrm{k} \text { cells average } \pm \mathrm{SE}\end{array}$ & $N$ & $\begin{array}{c}T \text {-test versus } \\
\text { ctrl }\end{array}$ \\
\hline A & Controls & $10.6 \pm 0.6$ & 8 & & $9.4 \pm 1.1$ & 8 & \\
\hline B & Controls & $8.7 \pm 0.3$ & 17 & & $7.7 \pm 0.3$ & 17 & \\
\hline $\mathrm{C}$ & Controls & $9.6 \pm 0.6$ & 8 & & $9.1 \pm 0.7$ & 8 & \\
\hline $\mathrm{D}$ & Controls & $7.8 \pm 0.7$ & 7 & & $8.2 \pm 0.8$ & 7 & \\
\hline All & Controls & $9.1 \pm 0.3$ & 40 & & $8.4 \pm 0.3$ & 40 & \\
\hline A & IFN $\gamma$ & & & & & & \\
\hline B & IFN $\gamma$ & $10.0 \pm 1.9$ & 8 & ns & $8.5 \pm 1.3$ & 8 & ns \\
\hline C & $\operatorname{IFN} \gamma$ & $8.3 \pm 0.4$ & 9 & ns & $6.7 \pm 0.6$ & 9 & 0.02 \\
\hline $\mathrm{D}$ & IFN $\gamma$ & $9.9 \pm 1.4$ & 2 & ns & $8.3 \pm 2.4$ & 2 & ns \\
\hline All & $\mathrm{IFN} \gamma$ & $9.2 \pm 0.8$ & 19 & ns & $7.6 \pm 0.6$ & 19 & $\mathrm{~ns}$ \\
\hline A & RT & & & & & & \\
\hline B & RT & $6.6 \pm 0.6$ & 8 & 0.01 & $4.4 \pm 0.5$ & 8 & 0.0001 \\
\hline C & $\mathrm{RT}$ & & & & & & \\
\hline $\mathrm{D}$ & $\mathrm{RT}$ & $5.6 \pm 0.3$ & 7 & 0.02 & $4.5 \pm 0.3$ & 7 & 0.002 \\
\hline All & RT & $6.1 \pm 0.4$ & 15 & $<0.001$ & $4.5 \pm 0.3$ & 15 & $<0.001$ \\
\hline A & $\mathrm{IFN} \gamma+\mathrm{RT}$ & & & & & & \\
\hline B & $\mathrm{IFN} \gamma+\mathrm{RT}$ & $7.4 \pm 1.0$ & 8 & ns & $5.7 \pm 0.5$ & 8 & 0.006 \\
\hline $\mathrm{C}$ & $\mathrm{IFN} \gamma+\mathrm{RT}$ & & & & & & \\
\hline $\mathrm{D}$ & $\mathrm{IFN} \gamma+\mathrm{RT}$ & & & & & & \\
\hline All & IFN $\gamma+$ RT & $7.4 \pm 1.0$ & 8 & ns & $5.7 \pm 0.5$ & 8 & $<0.01$ \\
\hline
\end{tabular}


TABLE 4: Specific therapeutic effect (STE) and apecific abscopal effect (SAE) in each experimental series and groups of treatment after immunization 3 times with syngeneic IFN $_{\gamma}$ secreting cells.

\begin{tabular}{|c|c|c|c|c|c|c|c|}
\hline $\begin{array}{l}\text { Experimental } \\
\text { series }\end{array}$ & $\begin{array}{l}\text { Group of } \\
\text { treatment }\end{array}$ & $\begin{array}{c}\text { No RT SAE Left } \\
\text { average } \pm \text { SE }\end{array}$ & $N$ & Left versus 0 & $\begin{array}{l}\text { RT }: \text { STE right } \\
\text { average } \pm \text { SE }\end{array}$ & $N$ & Right versus 0 \\
\hline A & RT & & & & & & \\
\hline B & $\mathrm{RT}$ & $0.24 \pm 0.06$ & 8 & 0.01 & $0.42 \pm 0.06$ & 8 & $<0.0005$ \\
\hline $\mathrm{C}$ & RT & & & & & & \\
\hline $\mathrm{D}$ & RT & $0.30 \pm 0.04$ & 7 & 0.001 & $0.49 \pm 0.04$ & 7 & $<0.0001$ \\
\hline All & RT & $0.33 \pm 0.04$ & 15 & $<0.0001$ & $0.46 \pm 0.04$ & 15 & $<0.0001$ \\
\hline $1-9 \mathrm{~A}$ & IMU-IFN $\gamma$ & & & & & & \\
\hline B & IMU-IFN $\gamma$ & $-0.17 \pm 0.23$ & 8 & ns & $-0.11 \pm 0.16$ & 8 & ns \\
\hline $\mathrm{C}$ & IMU-IFN $\gamma$ & $0.15 \pm 0.05$ & 9 & 0.02 & $0.26 \pm 0.07$ & 9 & ns \\
\hline $\mathrm{D}$ & IMU-IFN $\gamma$ & $-0.27 \pm 0.18$ & 1 & ns & $-0.02 \pm 0.29$ & 2 & ns \\
\hline All & IMUIFN $\gamma$ & $-0.01 \pm 0.09$ & 19 & ns & $0.09 \pm 0.07$ & 19 & \\
\hline $1-9 \mathrm{~A}$ & IMU-IFN $\gamma+$ RT & & & & & & \\
\hline B & IMU-IFN $\gamma+$ RT & $0.14 \pm 0.12$ & 8 & 0.01 & $0.26 \pm 0.07$ & 8 & ns \\
\hline $\mathrm{C}$ & IMU-IFN $\gamma+$ RT & & & & & & \\
\hline $\mathrm{D}$ & IMU-IFN $\gamma+$ RT & & & & & & \\
\hline All & IMU-IFN $\gamma+$ RT & $0.14 \pm 0.12$ & 8 & 0.001 & $0.26 \pm 0.07$ & 8 & $\mathrm{~ns}$ \\
\hline
\end{tabular}

TABle 5: Proliferation measured as counts per minute, in spleen cells harvested from rats taken from the various groups of rats (No.: number of rats evaluated in each group).

\begin{tabular}{lcccccccccccc}
\hline \multirow{2}{*}{ No. added spleen cells } & \multicolumn{3}{c}{ Control } & \multicolumn{3}{c}{ IFN $\gamma$} & \multicolumn{3}{c}{ RT } & \multicolumn{3}{c}{ IFN $\gamma+$ RT } \\
& Ave & SD & No. & Ave & SD & No. & Ave & SD & No. & Ave & SD & No. \\
\hline 450000 & 35 & \pm 23 & 6 & 206 & \pm 172 & 5 & 37 & \pm 18 & 5 & 60 & \pm 79 & 4 \\
150000 & 16 & \pm 14 & 6 & 94 & \pm 54 & 5 & 27 & \pm 36 & 5 & 54 & \pm 74 & 4 \\
50000 & 65 & \pm 120 & 6 & 75 & \pm 49 & 5 & 6 & \pm 15 & 5 & 22 & \pm 16 & 4 \\
\hline
\end{tabular}

4.2. Specific Therapeutic Effect and Specific Abscopal Effect. The "specific therapeutic effect" STE is obtained by normalizing the difference in tumor growth rate between the rightlateral controls and exposed tumors to the tumor growth rate of the right-lateral controls. The "specific abscopal effect" SAE is obtained by normalizing the difference in tumor growth rate between the left lateral controls and the unexposed tumor to the growth rate of the left lateral controls. The results of the specific therapeutic effect STE and the specific abscopal effect SAE are summarized in Table 4. These quantities are independent of time and normalized to the tumor growth characteristics of the controls of each experiment. In Figure 4, the averages of STE and SAE from each type of treatment are displayed.

4.2.1. Specific Therapeutic Effect (STE). For immunization alone with IFN $\gamma$ secreting tumor cells, the average STE value became $0.09 \pm 0.07$, which is not significantly different from zero. The combination of RT with immunization resulted in a STE value of $0.26 \pm 0.07$ which is not significantly different from zero. But the STE value 0.26 for the combination is significantly lower $(P<0.05)$ than the therapeutic effect of RT for which STE value is $0.46 \pm 0.04$.

4.2.2. Specific Abscopal Effect (SAE). The specific abscopal effect SAE of the contralateral untreated tumors in rats treated with RT alone became $0.33 \pm 0.04$, which is significantly different from zero $(P<0.001)$. For immunization with IFN $\gamma$-transfected tumor cells, there was no effect on the contra lateral tumor. The SAE value in this case was $-0.01 \pm 0.09$, which is not significantly different from zero. Immunization combined with $\mathrm{RT}$ resulted in a SAE value of $0.14 \pm 0.12$, which is neither significantly different from zero. Thus on the left tumor, there is no significant abscopal effect, of neither immunization alone nor immunization combined with RT.

4.3. Therapeutic (TER) and Abscopal Enhancement Ratio (AER). Our results do not show any enhanced non-target effects of radiation therapy combined with immunotherapy for extracranially implanted N29 glioma. But in another recent study with a similar model, the abscopal effect has been seen when RT is combined with immunotherapy [45]. In that study, it was found that fractioned $(3 \times 8 \mathrm{~Gy})$ or $(5 \times$ $6 \mathrm{~Gy}$ ) but not single-dose (20 Gy) RT induced an abscopal effect when the therapy was combined with anti-CTLA-4 antibodies in mice with colon and breast carcinoma cells. The reason why a single fraction of RT does not induce Abscopal effect might be the immunosuppressive function of immature myeloid cells $[16,46]$.

4.4. Mechanisms of the Abscopal Effect. The proliferation data given in Table 5 shows a significant enhancement 


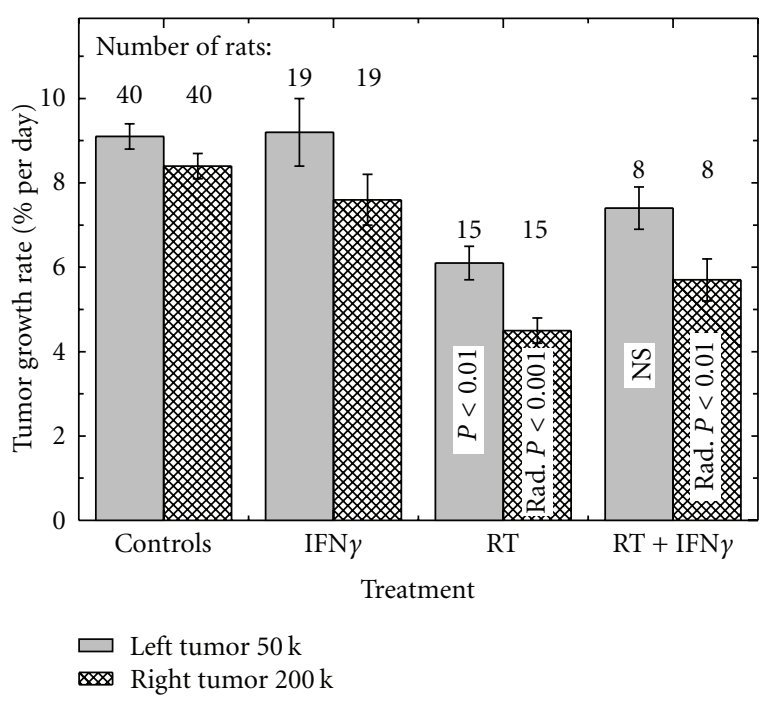

Figure 3: Tumor growth rate in rats with tumors in all series-A, -B, $-\mathrm{C}$, and $-\mathrm{D}$, with the average of the tumor growth rate for the four different treatment groups (controls, immunization (IMU-IFN $\gamma$ ), radiation therapy (RAD), or their combination (RAD + IMU-IFN $\gamma$ ) The averages of the TGR of the right lateral treated tumors is displayed in cross-pattern (right column), whereas the average of the tumor TGR of the corresponding untreated left-lateral tumors is displayed in gray (left column). The $P$-values ( $t$-test) in the columns correspond to the TGR of the animals in the different treatment groups versus the TGR of the corresponding controls.

when $150 \mathrm{k}$ spleen cell from IFN $\gamma$ cell immunized rat were analyzed. For the combination of RT and immunization with IFN $\gamma$ gene transfected cell, there is slightly enhanced proliferation, although not significant. After RT only, no significant increase in the proliferation of spleen cells could be detected. The abscopal effect, however, is significantly increased after RT treatment as a single therapy which might indicate that the abscopal effect of RT might be mediated by radiation-produced specific factors.

It has been suggested by others that the abscopal effect might depend upon secretoric or clastogenic factors in plasma samples from RT patients [47]. It has also been observed that cells exposed with ${ }^{60} \mathrm{Co} \gamma$-radiation produced a factor that mediates cell death in cells never exposed to radiation [11]. Other studies suggest that ionizing radiation induces the release of cytokines which mediate a systemic antitumor effect by activation of immune activity [33]. The existence of radiation-induced factors in vivo is now well accepted, and they are likely to be tissue and patient specific $[10,12]$. Studies of the abscopal effect also focus upon pivotal roles of increased ceramide levels, leading to apoptotic signaling [14, 48]. The absorbed dose of $20 \mathrm{~Gy}$ applied in the present study is comparable to the absorbed dose of $15 \mathrm{~Gy}$ which has been used to raise ceramide levels in circulation that might induce apoptotic death of cancer cells also in nonirradiated areas [49]. Numerous reports have revealed that activation of secretoric acid sphingomyelinase (sSMase) by chemotherapeutic agents resulted raising intracellular ceramide levels and increased death of cancer cells $[50,51]$.

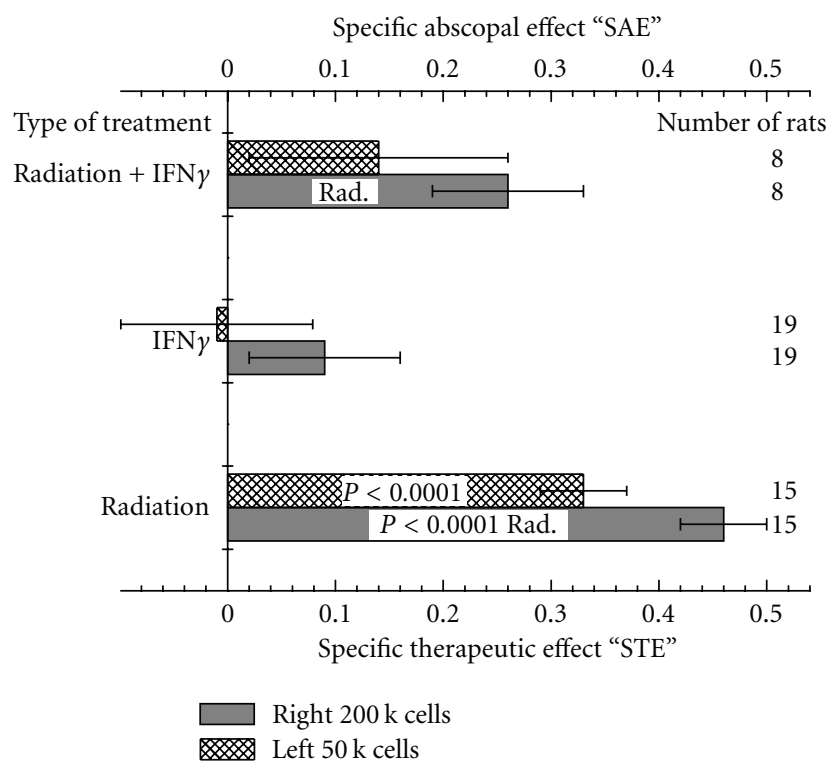

FIGURE 4: Specific therapeutic effect, STE (gray), and specific abscopal effect, SAE, (cross-pattern), from pooled data of series-B, $-C$, and $-D$. The $p$ values ( $t$-test) indicate the significance level of the STE and SAE being different from zero. No. is the number of rats in each group of various treatments.

Generation of ceramide by radiation therapy provides a novel target for the elimination of tumors and opens a new avenue of treatment in those patients who have developed multidrug resistant cancer [52].

Immune cells such as macrophages and $\mathrm{T}$ cells which are activated through radiation exposure secrete cytokines including Il-1, Il-6, and TNF $\alpha$, which lead to nitric-oxidesynthase (iNOS) activation and endogenous production of NO inside tumor cells. The nitric oxide NO diffuses out from the irradiated tumor and affects off-target tumor cells in a series of cascade reactions [34, 53]. It has been demonstrated that $\mathrm{NO}$ enhances the activation of the p53-dependent apoptotic program in tumor cells, which might be one of the mechanisms behind the abscopal effect [54]. Locally, enhancement of NO production has been used in a gene therapy approach by transfecting the iNOS gene into tumor cells combined with the radiation-inducible WAF1 promoter to drive the iNOS expression $[55,56]$.

Recent findings have also shown significant loss of global DNA methylation and a reduction of methyl-binding protein $\mathrm{MeCP} 2$ expression in both acutely radiation exposed and unexposed bystander spleen at $6 \mathrm{hr}, 96 \mathrm{hr}$, and 14 days after irradiation [57]. This indicates that epigenetic effects might also be involved in the mechanism of the abscopal effect.

In a recent Japanese study with tumors implanted s.c. in both flanks of ECI301 mice, chemokine (human macrophage inflammatory protein-1 alpha variant) was injected i.v. after local irradiation $(6 \mathrm{~Gy})$ at the contra-lateral flank only. In about $50 \%$ of the treated mice, the nonirradiated tumor was completely inhibited. Leukocyte depletion studies suggest that CD8+ and CD4+ lymphocytes and NK1 cells were 
TABLE 6: Time to sacrifice of rats in the various groups of experiment B.

\begin{tabular}{|c|c|c|c|c|c|c|c|c|c|c|c|c|}
\hline \multirow{2}{*}{ Time of survival } & \multicolumn{3}{|c|}{ Control } & \multicolumn{3}{|c|}{ IFN $\gamma$} & \multicolumn{3}{|c|}{ RT } & \multicolumn{3}{|c|}{$\mathrm{IFN} \gamma+\mathrm{RT}$} \\
\hline & Ave & $\mathrm{SD}$ & No. & Ave & SD & No. & Ave & SD & No. & Ave & $\mathrm{SD}$ & No. \\
\hline $1-13$ & 37 & \pm 8 & 16 & 56 & \pm 17 & 8 & 76 & \pm 10 & 8 & 86 & \pm 14 & 8 \\
\hline$t$-test versus control & & & & $P=0.02$ & & & $P<0.001$ & & & $P<0.001$ & & \\
\hline$t$-test versus control & & & & & & & $P<0.01$ & & & $P<0.005$ & & \\
\hline
\end{tabular}

involved. The results of that study indicate that chemokine administration after local irradiation might be useful for the treatment of advanced metastatic cancer [58]. It is thus apparent that tumor cells killed by the radiation contribute to establishing an immune response which is required for successful therapeutic effect and is partly protective. The immune response mediates the suppression of tumor cells outside the target area and affects the long-term survival of the patients. Recently, a functional relation was reported between the compounds HMGB1 released from the dying tumor cells activate the function of a toll like receptor (TLR4), which is important for the function of the immune system [59].

4.5. Time to Sacrifice. The time to sacrifice displayed in Table 6 indicates a significant increase of the time elapsed after inoculation until the rat was euthanized. For rat treated with immunization only the time to sacrifice increased about $50 \%$ compared to the untreated controls and for rats treated with radiotherapy only, the survival time increased about $112 \%$. For the combined therapy (IMU-IFN $\gamma+$ RT), the survival time increased about $131 \%$. The average tumour size at time of sacrifice for the group of rats treated with IMU-IFN $\gamma$ both alone and in combination with RT was about the same as the controls, while the tumor volume was reduced about $30 \%$ in the group of rats treated with radiation only. Thus, there seems to be a significant therapy effect of all treatments and in particularly RT and the combination (IMU-IFN $\gamma+$ RT). But there was no significant difference in the time to sacrifice between RT only and the combined therapy (IMU-IFN $\gamma+\mathrm{RT}$ ) which is in agreement with the TGR data. The time of sacrifice, however, gives no information about the abscopal effect which was the primary aim of the study.

\section{Conclusion}

By treatment of single intracranial N29 glioma tumors with RT in combination with immune therapy using IFN $\gamma$ transfected tumors cells, $75 \%$ complete tumor remissions have previously been demonstrated $[37,38]$. That effect of radiation was related to diminishing the tumor's immunesuppression and enhanced the infiltration of activated T-cells affecting the tumor. In the present extracranial model with two contra-lateral tumors, it was hypothesized that activated $\mathrm{T}$ cells should also affect the left lateral unirradiated tumor. The results of RT alone appear as an abscopal effect with TGR decrease also in the contra-lateral un-irradiated tumor, which account for the abscopal effect. But in this model neither enhanced therapeutic nor abscopal effect was found by radiation therapy combined with immunotherapy using IFN $\gamma$-transfected tumor cells.

The mechanisms of RT-induced abscopal effect seems to be very complex involving several factors leading the activation of immune cells and apoptotic signaling $[5,14$, $34,45,48,53]$. However, the abscopal effect opens for new and more effective radiation therapy regimes for spread disease. The combination of RT with increased ceramide levels, chemokine drugs, immune therapy, and gene therapy in order to enhance the abscopal effect should be further investigated.

\section{Abbreviations}

\begin{tabular}{|c|c|}
\hline $\begin{array}{l}\mathrm{AER}= \\
\mathrm{SAE}_{\text {Experimental }} / \mathrm{SAE}_{\text {Independent }}\end{array}$ & $\begin{array}{l}\text { Abscopal } \\
\text { enhancement ratio }\end{array}$ \\
\hline Ctrl: & Control \\
\hline DC: & Dendritic cells \\
\hline Gy: & Gray (J/kg) \\
\hline IMU: & Immunization \\
\hline IFN $\gamma:$ & Interferon gamma \\
\hline i.p.: & Intraperitoneally \\
\hline RT: & Radiation therapy \\
\hline N29: & $\begin{array}{l}\text { Tumor cell line } \\
\text { induced by } \\
\text { administration of } \\
\text { ethyl-N-nitro } \\
\text { urea to pregnant } \\
\text { Fischer rats }\end{array}$ \\
\hline $\begin{array}{l}\mathrm{SAE}=1- \\
\text { TGR }_{\text {Un-Exposed }} / \text { TGR }_{\mathrm{Ctrl}}:\end{array}$ & $\begin{array}{l}\text { SAE: specific } \\
\text { abscopal } \\
\text { effect }\end{array}$ \\
\hline SSD: & $\begin{array}{l}\text { Source-to-skin } \\
\text { distance }\end{array}$ \\
\hline $\mathrm{STE}=1-\mathrm{TGR}_{\text {Exposed }} / \mathrm{TGR}_{\mathrm{Ctrl}}$ : & $\begin{array}{l}\text { STE: specific } \\
\text { therapeutic effect }\end{array}$ \\
\hline $\begin{array}{l}\mathrm{TER}= \\
\mathrm{STE}_{\text {Experimental }} / \mathrm{STE}_{\text {Independent }}:\end{array}$ & $\begin{array}{l}\text { TER: therapeutic } \\
\text { enhancement } \\
\text { ratio }\end{array}$ \\
\hline TGR: & $\begin{array}{l}\text { Tumor growth rate } \\
\% \text { per day }\end{array}$ \\
\hline TV: & Tumor volume \\
\hline UC: & $\begin{array}{l}\text { Unexposed } \\
\text { controls }\end{array}$ \\
\hline UE: & $\begin{array}{l}\text { Unexposed } \\
\text { tumors. }\end{array}$ \\
\hline
\end{tabular}




\section{Acknowledgments}

The authors thank Sussanne Strömblad and Catarina Blennow for excellent technical assistance. Financial support from the Swedish Cancer Society, the Hans and Märit Rausing Charitable Foundation, John and Augusta Persson Foundation for Medical Research, Berta Kamprads Foundation, Lund University Hospital's donation funds, and Faculty of Medicine at Lund University is gratefully acknowledged.

\section{References}

[1] J. M. Kaminski, E. Shinohara, J. B. Summers, K. J. Niermann, A. Morimoto, and J. Brousal, "The controversial abscopal effect," Cancer Treatment Reviews, vol. 31, no. 3, pp. 159-172, 2005.

[2] M. Takaya, Y. Niibe, S. Tsunoda et al., "Abscopal effect of radiation on toruliform para-aortic lymph node metastases of advanced uterine cervical carcinoma-a case report," Anticancer Research, vol. 27, no. 1, pp. 499-503, 2007.

[3] H. Suit, "The gray lecture 2001: coming technical advances in radiation oncology," International Journal of Radiation Oncology Biology Physics, vol. 53, no. 4, pp. 798-809, 2002.

[4] S. C. Formenti and S. Demaria, "Systemic effects of local radiotherapy," The Lancet Oncology, vol. 10, no. 7, pp. 718726, 2009.

[5] S. Demaria, B. Ng, M. L. Devitt et al., "Ionizing radiation inhibition of distant untreated tumors (abscopal effect) is immune mediated," International Journal of Radiation Oncology Biology Physics, vol. 58, no. 3, pp. 862-870, 2004.

[6] B. R.R. Persson, C. B. Koch, G. Grafstrom, C. Ceberg, and L. G. Salford, "Abscopal regression of subcutaneously implanted N29 rat glioma after treatment of the contra-lateral tumors with pulsed electric fields (PEF) or radiation therapy (RT) and their combinations (PEF+RT)," Cancer Therapy, vol. 2, pp. 533-548, 2004.

[7] B. R.R. Persson, C. B. Koch, G. Grafstrom, C. Ceberg, and L. G. Salford, "Abscopaleffect in subcutaneously implanted tumors (N29 glioma) in rats treated with combined radiation therapy; and/or immunization with tumor cells," in Proceedings of the 55th Annual Meeting of the Radiation Research Society, p. PS5.11, Savannah Ga, USA, 2009.

[8] H. Nagasawa and J. B. Little, "Unexpected sensitivity to the induction of mutations by very low doses of alpha-particle radiation: evidence for a bystander effect," Radiation Research, vol. 152, no. 5, pp. 552-557, 1999.

[9] H. Nagasawa and J. B. Little, "Induction of sister chromatid exchanges by extremely low doses of $\alpha$ - particles," Cancer Research, vol. 52, no. 22, pp. 6394-6396, 1992.

[10] C. Mothersill and C. Seymour, "Radiation-induced bystander and other non-targeted effects: novel intervention points in cancer therapy?" Current Cancer Drug Targets, vol. 6, no. 5, pp. 447-454, 2006.

[11] C. Mothersill and C. Seymour, "Radiation-induced bystander effects: past history and future directions," Radiation Research, vol. 155, no. 6, pp. 759-767, 2001.

[12] C. Mothersill and C. Seymour, "Radiation-induced bystander effects and adaptive responses - the Yin and Yang of low dose radiobiology?" Mutation Research-Fundamental and Molecular Mechanisms of Mutagenesis, vol. 568, no. 1, pp. 121128, 2004.
[13] E. I. Azzam, S. M. de Toledo, and J. B. Little, "Stress signaling from irradiated to non-irradiated cells," Current Cancer Drug Targets, vol. 4, no. 1, pp. 53-64, 2004.

[14] M. E. Peters, M. M. Shareef, S. Gupta et al., "Potential utilization of bystander/abscopal-mediated signal transduction events in the treatment of solid tumors," Current Signal Transduction Therapy, vol. 2, no. 2, pp. 129-143, 2007.

[15] A. R. Snyder, "Review of radiation-induced bystander effects," Human and Experimental Toxicology, vol. 23, no. 2, pp. 87-89, 2004.

[16] S. Kusmartsev and D. I. Gabrilovich, "Immature myeloid cells and cancer-associated immune suppression," Cancer Immunology, Immunotherapy, vol. 51, no. 6, pp. 293-298, 2002.

[17] C. A. Waldren, "Classical radiation biology dogma, bystander effects and paradigm shifts," Human and Experimental Toxicology, vol. 23, no. 2, pp. 95-100, 2004.

[18] J. Rzeszowska-Wolny, W. M. Przybyszewski, and M. Widel, "Ionizing radiation-induced bystander effects, potential targets for modulation of radiotherapy," European Journal of Pharmacology, vol. 625, no. 1-3, pp. 156-164, 2009.

[19] S. Burdak-Rothkamm and K. M. Prise, "New molecular targets in radiotherapy: DNA damage signalling and repair in targeted and non-targeted cells," European Journal of Pharmacology, vol. 625, no. 1-3, pp. 151-155, 2009.

[20] S. Kusmartsev and D. I. Gabrilovich, "Role of immature myeloid cells in mechanisms of immune evasion in cancer," Cancer Immunology, Immunotherapy, vol. 55, no. 3, pp. 237$245,2006$.

[21] J. Antoniades, L. W. Brady, and D. A. Lightfoot, "Lymphangiographic demonstration of the abscopal effect in patients with malignant lymphomas," International Journal of Radiation Oncology Biology Physics, vol. 2, no. 1-2, pp. 141-147, 1977.

[22] G. Ehlers and M. Fridman, "Abscopal effect of radiation in papillary adenocarcinoma," British Journal of Radiology, vol. 46, no. 543, pp. 220-222, 1973.

[23] D. P. Kingsley, "An interesting case of possible abscopal effect in malignant melanoma," British Journal of Radiology, vol. 48, no. 574, pp. 863-866, 1975.

[24] M. P. Nobler, "The abscopal effect in malignant lymphoma and its relationship to lymphocyte circulation," Radiology, vol. 93, no. 2, pp. 410-412, 1969.

[25] K. Ohba, K. Omagari, T. Nakamura et al., "Abscopal regression of hepatocellular carcinoma after radiotherapy for bone metastasis," Gut, vol. 43, no. 4, pp. 575-577, 1998.

[26] G. J. Rees, "Abscopal regression in lymphoma: a mechanism in common with total body irradiation?" Clinical Radiology, vol. 32, no. 4, pp. 475-480, 1981.

[27] G. J. Rees and C. M. Ross, "Abscopal regression following radiotherapy for adenocarcinoma," British Journal of Radiology, vol. 56, no. 661, pp. 63-66, 1983.

[28] R. L. Sham, "The abscopal effect and chronic lymphocytic leukemia," American Journal of Medicine, vol. 98, no. 3, pp. 307-308, 1995.

[29] S. E. Cotter, G. P. Dunn, K. M. Collins et al., "Abscopal effect in a patient with metastatic Merkel cell carcinoma following radiation therapy," Journal of Investigative Dermatology, vol. 130, p. 688, 2010.

[30] P. Wersäll, H. Blomgren, P. Pisa, I. Lax, K. M. Kälkner, and C. Svedman, "Regression of non-irradiated metastases after extracranial stereotactic radiotherapy in metastatic renal cell carcinoma," Acta Oncologica, vol. 45, no. 4, pp. 493-497, 2006. 
[31] R. J. Mole, "Whole body irradiation-radiobiology or medicine?" The British Journal of Radiology, vol. 26, no. 305, pp. 234-241, 1953.

[32] R. M. Macklis, P. M. Mauch, S. J. Burakoff, and B. R. Smith, "Lymphoid irradiation results in long-term increases in natural killer cells in patients treated for Hodgkins-disease," Cancer, vol. 69, no. 3, pp. 778-783, 1992.

[33] A. Uchida, Y. Mizutani, M. Nagamuta, and M. Ikenaga, "Effects of X-ray irradiation on natural killer (NK) cell system. 2. Increased sensitivity to natural killer cytotoxic factor (NKCF)," Immunopharmacology and Immunotoxicology, vol. 11, no. 2-3, pp. 521-534, 1989.

[34] K. M. Prise and J. M. O'Sullivan, "Radiation-induced bystander signalling in cancer therapy," Nature Reviews Cancer, vol. 9, no. 5, pp. 351-360, 2009.

[35] S. C. Formenti, K. Friedman, K. Chao et al., "Abscopal response in irradiated patients: results of a proof of principle trial," in Proceedings of the 50th Annual Meeting of the American-Society-for-Therapeutic-Radiology-and Oncology, Elsevier Science, Boston, Mass, USA, 2008.

[36] S. Teitz-Tennenbaum, Q. Li, R. Okuyama et al., "Mechanisms involved in radiation enhancement of intratumoral dendritic cell therapy," Journal of Immunotherapy, vol. 31, no. 4, pp. 345358, 2008

[37] B. R. R. Persson, C. B. Koch, G. Grafström et al., "Survival of rats with N29 brain tumors after irradiation with 5 or 15 Gy and immunization with IFN- $\gamma$ secreting tumor cells," in Proceedings of the 1st International Conference on BioMedical Engineering and Informatics (BMEI '08), vol. 2, IEEE Computer Society, Hainan, China, 2008.

[38] B. R. R. Persson, C. B. Koch, G. Grafström et al., "Radiation immunomodulatory gene tumor therapy of rats with intracerebral glioma tumors," Radiation Research, vol. 173, no. 4, pp. 433-440, 2010.

[39] B. R. R. Persson, C. B. Koch, G. Grafström, C. Ceberg, B. Widegren, and L. Salford, "Abscopaleffect in subcutaneously implanted tumors (N29 glioma) in rats treated with combined radiation therapy; and/or immunization with tumor cells," in Proceedings of the 55th Annual Meeting of the Radiation Research Society, Savannah, Ga, USA, 2009.

[40] E. Visse, P. Siesjö, B. Widegren, and H. O. Sjögren, "Regression of intracerebral rat glioma isografts by therapeutic subcutaneous immunization with interferon- $\gamma$, interleukin-7, or B71-transfected tumor cells," Cancer Gene Therapy, vol. 6, no. 1, pp. 37-44, 1999.

[41] B. R. R. Persson, C. B. Koch, G. Grafström, P. E. Engström, and L. G. Salford, "A model for evaluating therapeutic response of combined cancer treatment modalities: applied to treatment of subcutaneously implanted brain tumors (N32 and N29) in Fischer rats with pulsed electric fields (PEF) and (CO)-C-60gamma radiation (RT)," Technology in Cancer Research and Treatment, vol. 2, no. 5, pp. 459-470, 2003.

[42] M. R. Graf, R. M. Prins, W. T. Hawkins, and R. E. Merchant, "Irradiated tumor cell vaccine for treatment of an established glioma. I. Successful treatment with combined radiotherapy and cellular vaccination," Cancer Immunology, Immunotherapy, vol. 51, no. 4, pp. 179-189, 2002.

[43] R. M. Prins, G. P. Scott, R. E. Merchant, and M. R. Graf, "Irradiated tumor cell vaccine for treatment of an established glioma. II. Expansion of myeloid suppressor cells that promote tumor progression," Cancer Immunology, Immunotherapy, vol. 51, no. 4, pp. 190-199, 2002.

[44] K. Lumniczky, S. Desaknai, L. Mangel et al., "Local tumor irradiation augments the antitumor effect of cytokine-producing autologous cancer cell vaccines in a murine glioma model," Cancer Gene Therapy, vol. 9, no. 1, pp. 44-52, 2002.

[45] M. Z. Dewan, A. E. Galloway, N. Kawashima et al., "Fractionated but not single-dose radiotherapy induces an immunemediated abscopal effect when combined with anti-CTLA-4 antibody," Clinical Cancer Research, vol. 15, no. 17, pp. 53795388, 2009.

[46] D. I. Gabrilovich and S. Nagaraj, "Myeloid-derived suppressor cells as regulators of the immune system," Nature Reviews Immunology, vol. 9, no. 3, pp. 162-174, 2009.

[47] I. Emerit, R. Arutyunyan, N. Oganesian et al., "Radiationinduced clastogenic factors-anticlastogenic effect of Ginkgo biloba extract," Free Radical Biology and Medicine, vol. 18, no. 6, pp. 985-991, 1995.

[48] A. Haimovitz-Friedman, C. C. Kan, D. Ehleiter et al., "Ionizing radiation acts on cellular membranes to generate ceramide and initiate apoptosis," Journal of Experimental Medicine, vol. 180, no. 2, pp. 525-535, 1994.

[49] S. Sathishkumar, B. Boyanovsky, A. A. Karakashian et al., "Elevated sphingomyelinase activity and ceramide concentration in serum of patients undergoing high dose spatially fractionated radiation treatment-implications for endothelial apoptosis," Cancer Biology and Therapy, vol. 4, no. 9, pp. 979-986, 2005.

[50] Y. Goodman and M. P. Mattson, "Ceramide protects hippocampal neurons against excitotoxic and oxidative insults, and amyloid $\beta$-peptide toxicity," Journal of Neurochemistry, vol. 66, no. 2, pp. 869-872, 1996.

[51] W. D. Jarvis and S. Grant, "The role of ceramide in the cellular response to cytotoxic agents," Current Opinion in Oncology, vol. 10, no. 6, pp. 552-559, 1998.

[52] R. M. Laethem, Y. A. Hannun, S. Jayadev et al., "Increases in neutral, $\mathrm{Mg}^{2+}$-dependent and acidic, $\mathrm{Mg}^{2+}$-independent sphingomyelinase activities precede commitment to apoptosis and are not a consequence of caspase 3-like activity in Molt4 cells in response to thymidylate synthase inhibition by GW1843," Blood, vol. 91, no. 11, pp. 4350-4360, 1998.

[53] C. Shao, V. Stewart, M. Folkard, B. D. Michael, and K. M. Prise, "Nitric oxide-mediated signaling in the bystander response of individually targeted glioma cells," Cancer Research, vol. 63, no. 23, pp. 8437-8442, 2003.

[54] T. Cook, Z. Wang, S. Alber et al., "Nitric oxide and ionizing radiation synergistically promote apoptosis and growth inhibition of cancer by activating p53," Cancer Research, vol. 64, no. 21, pp. 8015-8021, 2004.

[55] Z. Wang, T. Cook, S. Alber et al., "Adenoviral gene transfer of the human inducible nitric oxide synthase gene enhances the radiation response of human colorectal cancer associated with alterations in tumor vascularity," Cancer Research, vol. 64, no. 4, pp. 1386-1395, 2004.

[56] J. Worthington, "Development of radiation-inducible promoters for use in nitric oxide synthase gene therapy of cancer," Journal of Gene Medicine, vol. 6, no. 9, p. 89, 2004.

[57] Y. Ilnytskyy, I. Koturbash, and O. Kovalchuk, "Radiationinduced bystander effects in vivo are epigenetically regulated in a tissue-specific manner," Environmental and Molecular Mutagenesis, vol. 50, no. 2, pp. 105-113, 2009.

[58] K. Shiraishi, Y. Ishiwata, K. Nakagawa et al., "Enhancement of antitumor radiation efficacy and consistent induction of the abscopal effect in mice by ECI301, an active variant of macrophage inflammatory protein-1 $\alpha$," Clinical Cancer Research, vol. 14, no. 4, pp. 1159-1166, 2008. 
[59] L. Apetoh, F. Ghiringhelli, A. Tesniere et al., "Toll-like receptor 4-dependent contribution of the immune system to anticancer chemotherapy and radiotherapy," Nature Medicine, vol. 13, no. 9, pp. 1050-1059, 2007. 


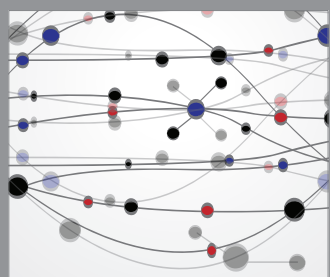

The Scientific World Journal
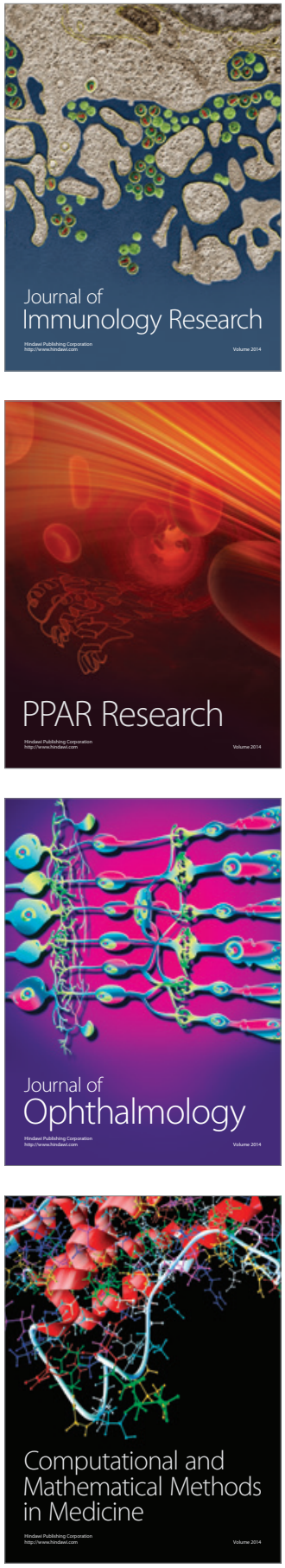

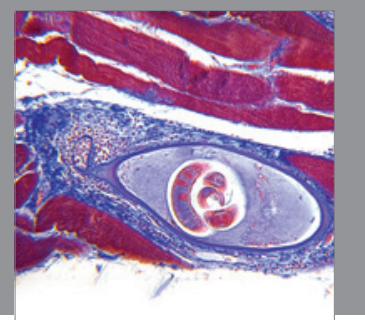

Gastroenterology

Research and Practice
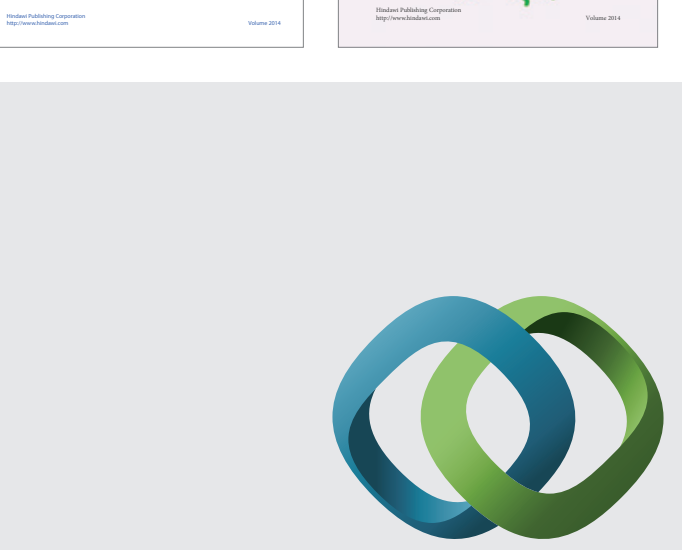

\section{Hindawi}

Submit your manuscripts at

http://www.hindawi.com
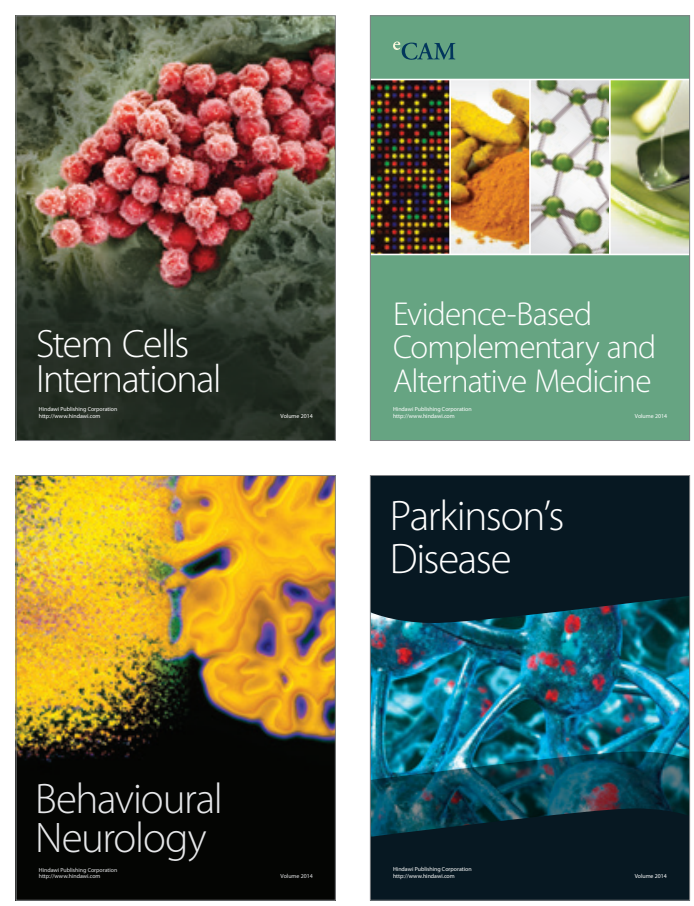

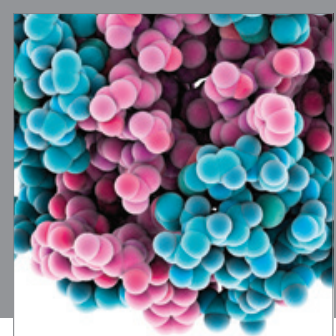

Journal of
Diabetes Research

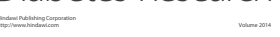

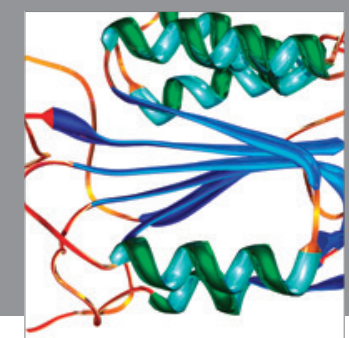

Disease Markers
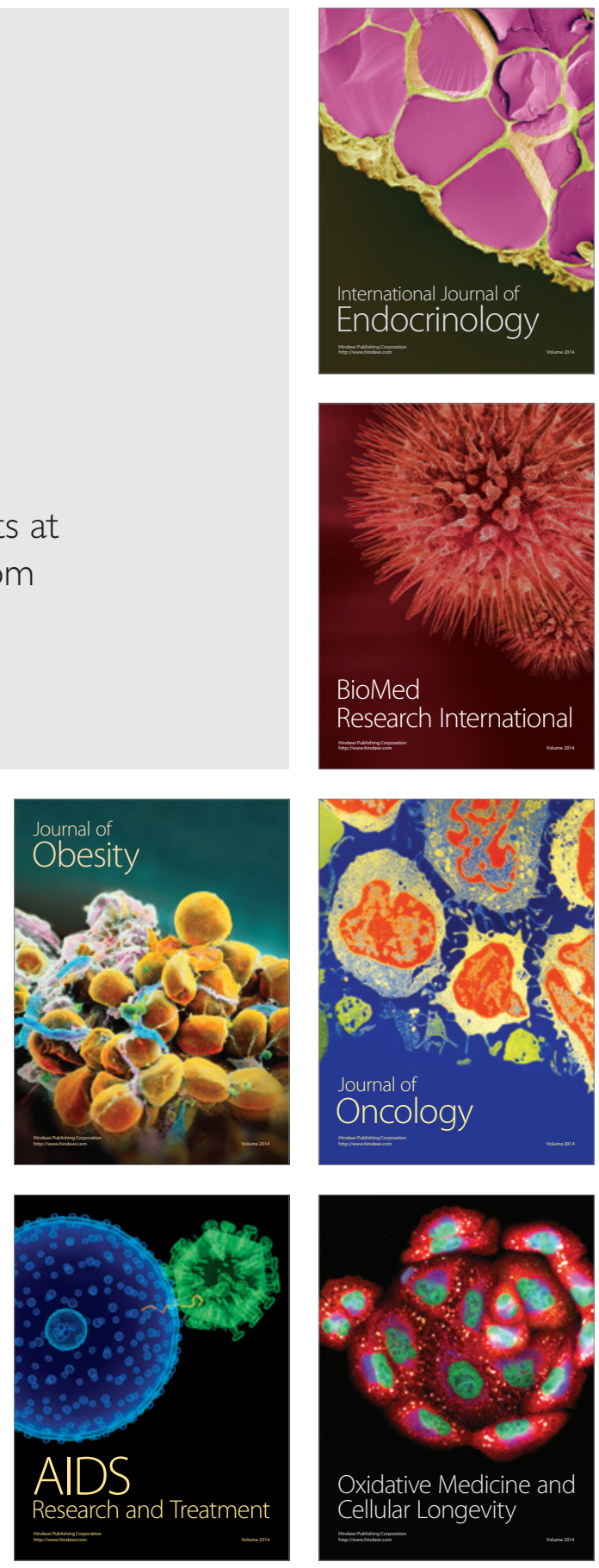